\title{
Perilaku Konsumtif Penggemar Korean Wave di Twitter (Studi Tentang Fenomena Koleksi Photocard K-Pop)
}

\author{
Devina Tanliana ${ }^{1}$, Lusia Savitri Setyo Utami2 ${ }^{*}$ \\ ${ }^{1}$ Fakultas Ilmu Komunikasi, Universitas Tarumanagara, Jakarta \\ Email: devina.915180229@stu.untar.ac.id \\ ${ }^{2}$ Fakultas Ilmu Komunikasi, Universitas Tarumanagara, Jakarta* \\ Email: lusias@fikom.untar.ac.id
}

Masuk tanggal : 15-12-2021, revisi tanggal : 06-01-2022, diterima untuk diterbitkan tanggal : 06-01-2022

\begin{abstract}
The entertainment industry is in great demand by all circles, including South Korea, bringing K-Pop to the world stage. The success of K-Pop has produced many fans in various parts of the world, including Indonesia. K-Pop can make fans as part of consumers or customers who loyally buy their music products. In recent years, the photocard collection phenomenon has been loved by K-Pop fans. A Photocard is a selfie photo of an idol on a card and is usually included in the album as a bonus. The social media Twitter is used by $K$ Pop fans as an information fulfillment on the trend of this collection. Having an extensive collection of Photocards causes the frequency of repeated purchases that lead to consumptive behavior. This study aims to describe the consumptive behavior that occurs on Twitter related to the phenomenon of photocard collection. Theoretical reviews used in this study are mass communication, new media, social media, uses and gratification theory, and consumptive behavior. To explore this phenomenon researcher used qualitative research approaches and phenomenological methods. Data were collection from in-depth interviews with four informants, participant observation and literature study. The results obtained indicate that Twitter is actively chosen as a medium for meeting the information needs of Photocard collection. Still, the impact of using Twitter has both positive and negative sides. Then, the motivation in doing the collection is based on the fulfillment of self-satisfaction that forms consumptive behavior.
\end{abstract}

Keywords: consumptive behaviour, K-Pop, photocard, social media, uses and gratification theory

\begin{abstract}
Abstrak
Industri hiburan sangat diminati semua kalangan, tak terkecuali negara Korea Selatan yang mampu membawa K-Pop ke kancah dunia. Kesuksesan K-Pop mencetak banyak penggemar di berbagai belahan dunia, termasuk Indonesia. K-Pop dapat menjadikan penggemar sebagai bagian dari konsumen atau pelanggan yang dengan setia membeli hasil produk musiknya. Dalam beberapa tahun terakhir fenomena yang sedang digandrungi oleh penggemar K-Pop adalah koleksi Photocard yang merupakan gambar swafoto idola yang berbentuk kartu dan biasanya berada di dalam album sebagai bonus. Media sosial Twitter dimanfaatkan penggemar K-Pop sebagai pemenuhan informasi atas trend koleksi ini. Memiliki banyak koleksi Photocard menyebabkan frekuensi pembelian secara berulang yang menimbulkan perilaku konsumtif. Tujuan penelitian ini adalah untuk mendeskripsikan perilaku konsumtif yang terjadi di Twitter terkait fenomena koleksi Photocard. Dalam pembahasannya, menggunakan komunikasi massa, new media, media sosial, teori uses and gratification, dan perilaku konsumtif. Untuk mendalami fenomena ini digunakan pendekatan penelitian kualitatif dan metode fenomenologi. Pengumpulan data diperoleh dari wawancara mendalam dengan empat informan, observasi partisipan dan studi kepustakaan. Hasil yang didapatkan
\end{abstract}


menunjukkan bahwa Twitter dipilih secara aktif sebagai media pemenuhan kebutuhan informasi koleksi Photocard, namun dampak penggunaan Twitter memiliki sisi positif dan negatif. Kemudian, motivasi dalam melakukan koleksi didasari pemenuhan kepuasan diri yang membentuk perilaku konsumtif.

Kata Kunci: K-Pop, media sosial, perilaku konsumtif, photocard, teori uses and gratification

\section{Pendahuluan}

Negeri ginseng Korea Selatan menarik mata dunia dengan budayanya dan membuat banyak individu ingin mempelajari bahasa, budaya, gaya hidup dengan datang ke Korea Selatan. Tak terkecuali Indonesia yang terkena dampak fenomena Korean Wave atau Hallyu. Salah satu industri hiburan yang berhasil membuat Korea sangat diminati oleh berbagai kalangan adalah K-Pop. Alhasil banyak penggemar tidak ragu untuk mengikuti suasana sensasional dari mencintai suatu musik dan mendukung idola berakhir membeli produk keluaran dari musik tersebut, hal ini dimanfaatkan beberapa pihak untuk mencari keuntungan dan menjadikan loyalitas penggemar sebagai nilai jual.

Aprilia \& Hartoyo (2013) mendefinisikan perilaku konsumtif adalah kegiatan mengonsumsi dan melakukan pemborosan secara berlebihan terhadap jasa atau barang yang tidak diperlukan secara tidak terencana. Saat pandemi covid-19 fenomena sedang berkembang di kalangan penggemar K-Pop adalah memiliki koleksi Photocard sebagai alternatif untuk mencari kesenangan dan menghilangkan kejenuhan. Semakin marak pula penggunaan Twitter yang dimanfaatkan penggemar untuk melancarkan kegiatan koleksi Photocard dengan berinteraksi dengan sesama kolektor. Penelitian ini bertujuan mengetahui dan mendekripskan perilaku konsumtif yang terjadi di Twitter terkait fenomena koleksi Photocard.

Penelitian ini menggunakan teori pendukung antara lain, komunikasi massa, new media, media sosial, teori uses and gratification, dan perilaku konsumtif. Komunikasi massa menurut Jay Black dan Frederick C. Whitney (1988) dalam Jefta Ahfadyusron (2017) mengemukakan bahwa komunikasi massa adalah proses produksi pesan dalam jumlah banyak atau massal, dan penerima pesan berjangka luas, bermacam - macam dan bersifat anonim. Dalam penggunaan media sosial terkhususnya Twitter terdapat efek - efek yang ditimbulkan seperti efek kognitif, afektif, dan behavioral.

Teori uses and gratification menurut Katz (1974) dalam Humaizi (2018) menyatakan teori Uses and Gratification memandang khalayak sebagai individu yang aktif dan memilih tujuan, yaitu memenuhi kebutuhan juga kepentingannya. Kemudian, terdapat 4 motif pengonsumsian data, yaitu : 1) informasi 2) identitas pribadi 3) integritas \& interaksi sosial, serta 4) hiburan.

Akibat dari penggunaan Twitter sebagai media pemenuhan kebutuhan membentuk perilaku konsumtif yang didefinisikan oleh Ancok (1995) dalam Aini (2018) sebagai perilaku individu yang tidak dapat menahan rasa ingin untuk mengkonsumsi barang atau jasa tanpa memperhatikan fungsi utamanya. Aspek dari perilaku konsumtif menurut Lina \& Rosyid (1997) dalam Thohiroh (2015) terdiri dari pembelian impulsif, pemborosan, dan mencari kesenangan. Kemudian, timbulnya perilaku konsumtif ditandai dengan ciri menurut Fromm dalam Yulianti (2021) antara lain sebagai pemenuh keinginan, barang di luar jangkauan, barang tidak produktif dan dipergunakan untuk menaikkan status. 


\section{Metode Penelitian}

Penelitian ini menggunakan pendekatan kualitatif dengan metode penelitian fenomenologi. Metode penelitian yang digunakan adalah fenomenologi karena bertujuan menjelaskan dan menggambarkan fenomena spesifik yaitu perilaku konsumtif dalam fenomena koleksi Photocard yang didapat dari pengalaman hidup dan perspektif penggemar K-Pop di era ini. Subyek dari penelitian ini adalah penggemar K-Pop dikarenakan penggemar K-Pop sangat mengerti dan menggemari fenomena mengoleksi Photocard, dan obyek penelitiannya adalah perilaku konsumtif dalam fenomena koleksi Photocard di Twitter. Dalam proses pengumpulan data, penulis melakukan wawancara mendalam dengan 4 informan yang memenuhi kriteria sebagai berikut: (1) Usia 21 - 25 tahun; (2) Pengguna media sosial Twitter; (3) Memiliki koleksi Photocard.

Data lainnya diperoleh dari observasi partisipan yang dilakukan penulis di media sosial Twitter untuk mengamati fenomena koleksi Photocard. Selain itu, untuk menunjang penelitian sumber didapatkan dari studi kepustakaan untuk memperdalam wawasan dan pengetahuan penulis untuk menjawab permasalahan penelitian. Dalam teknik pengolahan data, penulis melakukan reduksi data penulis menggolongkan hasil wawancara dengan narasumber dan merangkum data yang merupakan garis besar permasalahan. Kemudian, penulis memaparkan hasil reduksi dan terakhir penarikan kesimpulan yang merupakan hasil dari penelitian untuk menjawab inti permasalahan yang berasal dari analisis data. Untuk membuktikan kebenaran dari penelitian ini, teknik keabsahan data yang dipergunakan yakni triangulasi sumber data dengan dilakukannya penggalian data dari narasumber yang berbeda yaitu 4 penggemar K-Pop dari berbagai latar belakang, narasumber pendukung ahli, hasil observasi dari Twitter dan teori yang terdapat studi kepustakaan.

\section{Hasil Temuan dan Diskusi}

Hasil temuan yang didapatkan oleh penulis dari wawancara mendalam dengan keempat informan, sebagai berikut:

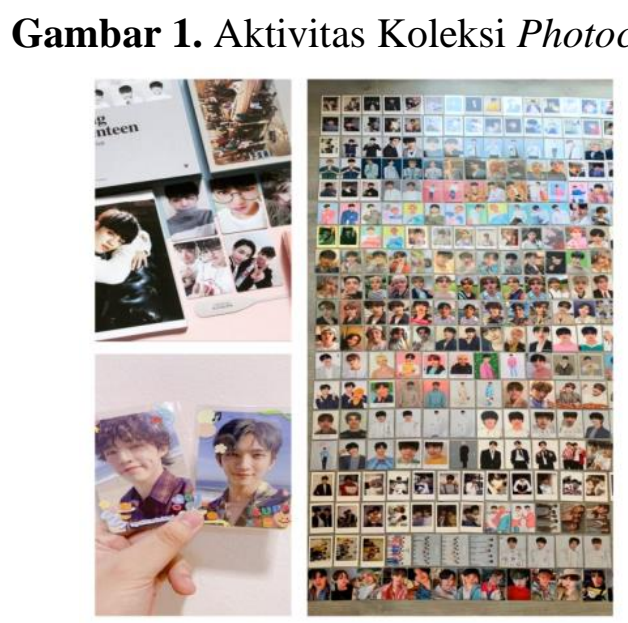

Sumber: Dokumentasi Pribadi 


\section{Aktivitas Memulai Photocard}

a. Awal Memulai Koleksi

Informan I dan IV memulai dengan mengetahuinya dari Twitter dan rekomendasi dari temannya, Informan II menemukan kesenangan pribadinya dalam mengoleksi saat pandemi, informan III mendapatkan pengaruh dari media sosial Instagram dan Twitter karena unggahan kolektor lain yang disukainya.

b. Motivasi mengoleksi Photocard

Semua informan memiliki ambisi setelah memulai koleksi pertama dengan alasan menginginkan binder yang terisi penuh dan mendapat kepuasan hati dari koleksi yang lengkap.

c. Nilai Photocard di mata kolektor

Informan I, III, dan IV merasa koleksinya sangat berharga dan akan dijaga sebaik mungkin agar tidak mengalami kerusakan, namun informan II memiliki pendapat bahwa sebatas barang koleksi saja tidak perlu diagung agungkan secara berlebihan.

d. Rencana untuk koleksi Photocard

Informan I dan III sudah berencana untuk berhenti dalam beberapa waktu kedepan, berbeda dengan informan II dan IV yang masih menemukan kesenangan dalam mengoleksi Photocard dan belum terpikirkan untuk berhenti dari mengoleksi Photocard.

\section{Penggunaan Twitter sebagai Pemenuhan Kebutuhan Koleksi Photocard}

a. Alasan penggunaan Twitter

Alasan informan I menggunakan Twitter karena terdapat banyak penjual luar negeri yang menawarkan harga terjangkau, Informan II memilih Twitter karena berbasis tulisan sehingga mudah untuk mencari kata kunci, pendapat serupa dilontarkan informan II, III, dan IV yang setuju Twitter merupakan tempat yang mudah untuk berinteraksi dan media sosial terupdate untuk melakukan kegiatan jual - beli Photocard.

b. Informasi yang didapatkan dari Twitter

Informasi yang diperoleh informan I berupa daftar Photocard terbaru dan memanfaat fitur autobase yang dimanfaatkan untuk berbagi informasi penjualan Photocard secara anonim, Informan II mendapatkan himbauan dari pengguna lain untuk berhati - hati terhadap penipuan, Informan III dan IV memperoleh informasi serupa berupa template / preview Photocard beserta keterangan harganya.

\section{Perilaku Konsumtif akibat Penggunaan Twitter}

a. Penggunaan Twitter dalam melakukan pembelian

Semua informan setuju bahwa Twitter berperan besar untuk melakukan pembelian yang berikutnya, meskipun kartu tersebut sebelumnya tidak termasuk ke dalam prioritasnya.

b. Perubahan perilaku akibat penggunaan Twitter

Semua informan merasakan perubahan menjadi lebih boros dan impulsif dikarenakan semua pengeluaran yang sebelumnya dapat dipergunakan untuk sesuatu yang lebih bernilai, dikeluarkan hanya untuk koleksi Photocard. 
Dari hasil temuan tersebut dapat dijabarkan dengan menggunakan teori teori penunjang yang digunakan dalam penelitian ini, sebagai berikut:

\section{Penggunaan Twitter untuk Memenuhi Kebutuhan Informasi}

Teori Uses and Gratification menurut Katz (1974) dalam Humaizi (2018) memandang khalayak sebagai individu yang aktif dan memilih tujuan, yaitu memenuhi kebutuhan juga kepentingannya. Dalam kaitannya dengan teori ini, informan memilih Twitter sebagai media yang dipercayanya untuk memenuhi kebutuhan informasi. Terdapat 4 motif pengonsumsian media Twitter, antara lain:

a. Motif Informasi

Motif pengonsumsian media menurut McQuail dalam Humaizi (2018) untuk mencari informasi yakni untuk memenuhi kepuasaannya akan pengetahuan, mencari bimbingan dalam menyelesaikan masalah praktis. Informasi yang diperoleh informan berupa template, informasi trading, dan keterangan harga.

b. Motif Identitas Pribadi

McQuail dalam Humaizi (2018) motif ini dipergunakan untuk menemukan pedoman perilaku yang dipilihnya dan pengidentifikasian diri. 2 informan mengidentifikasi dirinya sebagai kolektor sejati, dan 3 informan merasa koleksinya sangat berharga serta memahami value dari koleksinya yang membedakan cara pandangnya dari orang awam.

c. Motif Integritas dan Interaksi Sosial

Motif Integritas dan Interaksi Sosial menurut McQuail dalam Humaizi (2018) yakni untuk melakukan interaksi dengan individu lain memperoleh kabar mengenai orang lain, mempererat rasa solidaritas. Fungsi utama dari Twitter adalah untuk berinteraksi dengan pengguna lain serta dengan tersedianya autobase mempermudah interaksi dengan mencakup pengguna lain yang memiliki informasi terkait. Beberapa informan bertemu dengan pengguna yang mempunyai kegemaran dengan K-Pop menjadi mutual bahkan ada yang menjalin persahabatan di dunia nyata.

d. Motif Hiburan

Motif Hiburan menurut McQuail dalam Humaizi (2018) dalam mengonsumsi media yaitu individu mengonsumsi media sebagai pelepasan dari masalah, untuk mengisi waktu luang dengan bersantai. Beberapa informan menganggap koleksi Photocardnya sebagai sarana melepas stress dengan melihat unggahan kolektor lain yang memiliki koleksi - koleksi menarik di Twitter, kemudian informan lain merasa mendapatkan kesenangan diri dengan membuat konten hiburan mengenai koleksinya yang nantinya akan diunggah di Twitter.

\section{Efek Komunikasi Massa Akibat Penggunaan Twitter}

a. Efek Kognitif

Efek Kognitif dalam Dini (2018) merupakan efek yang bersifat informatif dan dapat mengembangkan kemampuan kognitif. Penyebaran informasi Twitter yang cukup cepat, dimanfaatkan pengguna untuk menghimbau pengguna lain agar berwaspada terhadap penipuan melalui utas/thread.

b. Efek Afektif

Dalam Dini (2018) efek afektif merupakan informasi yang disampaikan berada di tahap afektif yang menyangkut penilaian, emosi dan perilaku. 
Terdapat informan yang sebelumnya tidak memahami mengapa mengoleksi sebuah kertas, kemudian berubah pikiran dan memiliki ambisi besar untuk melengkapi koleksinya. Setelah berhasil melengkapi koleksinya, informan akan merasa senang dan bangga namun kesenangannya bersifat temporer.

c. Efek Behavioral

Efek Behavioral dalam Dini (2018) muncul akibat dari dampak media kepada perilaku dan tindakan khalayak. Dampak ini dapat terlihat dalam gerak gerik, tingkah laku dan kegiatan seseorang dalam kehidupan sehari - harinya. Informan menyerap informasi - informasi yang didapatnya dari Twitter kemudian secara otomatis menstimulus informan untuk melakukan pembelian secara terus - menerus. Selain itu, perilaku lain yang ditunjukkan adalah perubahan perilaku yang sebelumnya rajin menabung dan merawat diri menjadi pribadi sering menghamburkan uang untuk membeli Photocard.

\section{Perilaku Konsumtif sebagai Dampak Aktivitas Koleksi Photocard}

Penulis melakukan wawancara dengan narasumber ahli, Willy Tasdin M.Psi., Psikolog. Beliau memberikan pendapatnya mengenai perilaku konsumtif terkait fenomena koleksi Photocard dalam ranah psikologi yang dapat mendukung penelitian.

a. Pembelian Impulsif

Menurut Lina \& Rosyid (1997) dalam Thohiroh (2015) pembelian impulsif adalah melakukan pembelian yang tidak terencana sebelumnya dan tanpa berpikir panjang. Kebiasaan ini dilakukan oleh semua informan yang tergiur dengan tweet penjualan Photocard yang bukan prioritasnya. Beberapa informan juga turut ikut mengoleksi Photocard idola lain yang dianggap memiliki nilai pasar yang baik. Perilaku impulsif juga muncul saat menemukan penjual yang menawarkan harga - harga terjangkau, melakukan pembelian dalam jumlah besar yang menyebabkan tagihan yang bengkak. Hal ini juga termasuk ke dalam ciri barang di luar jangkauan.

b. Pemborosan

Pemborosan menurut Lina \& Rosyid (1997) dalam Thohiroh (2015) merupakan kegiatan menghamburkan uang tanpa tujuan yang jelas dan di luar kebutuhannya. Pemborosan terjadi saat memiliki ambisi yang tinggi untuk memenuhi binder, melakukan pembelian dalam jumlah banyak yang kemudian setelah dibeli hanya disimpan dan barang menjadi tidak produktif. Jika dibiarkan dalam jangka panjang akan menyebabkan Hoarding Disorder ditandai dengan memiliki hasrat mengumpulkan barang dan sulit membuang benda - benda yang tidak diperlukan.

c. Mencari Kesenangan

Alasan untuk memulai koleksi Photocard didasari dengan rasa senang dan mencari kepuasan diri. Beberapa informan merasa dengan mengoleksi dapat menjadi pelepasan dari stress dan menaikkan mood dan adapun yang memiliki keinginan untuk melengkapi koleksinya dan membanggakannya di media sosial merupakan ciri perilaku konsumtif untuk menaikkan status agar diakui. Namun, menurut narasumber ahli cara coping seperti ini tidak akan mengobati stress dan merupakan siklus berulang. Mendapatkan kesenangan dari kegiatan fangirling seperti merasa dekat dengan idola setelah memiliki Photocardnya. Menurut narasumber ahli, hal ini sudah termasuk ke dalam Celebrity Worship Disorder yang memiliki obsesi adiktif kepada idola dan 
karena obsesi yang sangat besar ini, seseorang dapat melupakan dirinya sendiri atau kehilangan selfcare.

\section{Simpulan}

Twitter dipilih secara aktif oleh kolektor Photocard sebagai pemenuhan informasi dikarenakan memiliki fitur terdepan, tempat yang nyaman untuk berinteraksi, dan informasi kegiatan jual - beli yang sangat up to date. Namun, akibat penggunaan Twitter memiliki sisi positif seperti mendapatkan pengetahuan baru dan sisi negatif yang membentuk pola perilaku konsumtif. Motivasi dari mengoleksi Photocard beragam tetapi didasari dengan rasa senang atau hobi namun menjadi obsesi yang tidak sehat sehingga membentuk pola perilaku konsumtif. Untuk penelitian selanjutnya, penulis berharap dapat membahas secara lebih mendalam mengenai interaksi antar penggemar di Twitter dalam kaitannya dengan fenomena koleksi Photocard serta dapat memilah informasi sebaik - baiknya, memanfaatkan media sosial Twitter untuk membuat komunitas virtual yang sehat,

\section{Ucapan Terima Kasih}

Peneliti ingin mengucapkan terima kasih kepada Fakultas Ilmu Komunikasi Universitas Tarumanagara, narasumber, serta semua pihak yang turut membantu peneliti sehingga penelitian ini dapat diselesaikan.

\section{Daftar Pustaka}

Aini, R. D. (2016). Kontrol Diri dan Perilaku Konsumtif pada Mahasiswa Universitas "X" di Yogyakarta. (Doctoral Dissertation, UII Yogyakarta).

Aprilia, D. \& H. (2013). Analisis Sosiologis Perilaku Konsumtif Mahasiswa (Studi pada Mahasiswa FISIP Universitas Lampung). Jurnal Sosiologi.

Humaizi. (2018). Uses and Gratifications Theory. USU Press.

Jefta Ahfadyusron, M. (2017). Efektivitas Fungsi Humas Pemerintah Kabupaten Jember Dalam Membangun Komunikasi Dengan Masyarakat Melalui Media Massa. (Doctoral Dissertation, Universitas Muhammadiyah Jember).

Setyanto, Y., Winduwati, S \& Utami, L. S. S. (2017). Early Adolescent Behavior on Media Toward Idol Figure (Parasocial Study on Preliminary Youth as an Effect of New Media). International Journal of Communication and Media Studies, 7(2), 1-14.

Thohiroh, A. Q. (2015). Perilaku Konsumtif Melalui Online Shopping Fashion Pada Mahasiswi Fakultas Psikologi Universitas Muhammadiyah Surakarta. (Doctoral Dissertation, Universitas Muhammadiyah Surakarta).

Veronica, M., \& Paramita, S. (2019). Eksploitasi Loyalitas Penggemar Dalam Pembelian Album K-Pop. Koneksi, 2(2), 433.

Yulianti, I. (2021). Pengaruh E-commerce Shopee Terhadap Perilaku Konsumtif (Studi Pada Mahasiswa Fakultas Ekonomi Dan Bisnis Islam 2018-2020 UIN SMH Banten). (Doctoral Dissertation, UIN SMH BANTEN). 